\title{
Estudo etnobotânico de plantas medicinais na comunidade faxinalense Sete Saltos de Baixo, Ponta Grossa - PR
}

\author{
Estudio etnobotánico de las plantas medicinales en la \\ comunidad faxinalense Sete Saltos de Baixo, Ponta Grossa - PR
}

\author{
Ethnobotanical study of medicinal plants in the faxinal \\ community Sete Saltos de Baixo, Ponta Grossa, PR
}

\author{
Adelita Staniski \\ adelitasta@hotmail.com \\ Mestranda do PPG em Geografia da UEPG \\ Nicolas Floriani \\ florianico@gmail.com \\ Professor Doutor do PPG em Geografia da UEPG \\ Juliano Strachulski \\ julianomundogeo@gmail.com \\ Doutorando do PPG em Geografia da UEPG
}

\begin{abstract}
Resumo: Este estudo etnobotânico buscou investigar os conhecimentos tradicionais sobre plantas medicinais na Comunidade Faxinalense Sete Saltos de Baixo, localizada no distrito de Itaiacoca, Ponta Grossa - PR. Para a realização da pesquisa, foram utilizadas técnicas participativas, com aplicação de entrevistas e a realização de coleta de espécies com moradores da comunidade, além da posterior identificação científica. A pesquisa registrou um total de 51 etnoespécies apontadas pelos moradores como de uso medicinal, sendo que as mais citadas foram as das famílias Asteraceae e Lauraceae, encontradas nas hortas-quintais. A parte mais utilizada das plantas foi a folha, enquanto a forma de preparo mais comum foi o chá, que combate principalmente gripe, dores de estômago, dores de barriga e infecções.
\end{abstract}

Palavras-chave: Conhecimento Tradicional. Etnobotânica. Plantas Medicinais.

Resumen: El presente estudio etnobotánico trató de investigar los conocimientos tradicionales acerca de las plantas medicinales en la Comunidad Faxinalense Sete Saltos de Baixo, situada en el distrito de Itaiacoca, Ponta Grossa - PR. Para la realización de la investigación, se utilizaron técnicas participativas, con aplicación de entrevistas y la recogida de las especies con los residentes de la comunidad, además de la posterior identificación científica. La encuesta registró un total de 51 ethnospecies identificados por los residentes como de uso medicinal, y las más citadas fueron de la familia de las Asteraceae y Lauraceae, que se encuentran en huertos-quintas. La parte más utilizada de las plantas fue la hoja, mientras que la forma más común de preparación es el té, que combate principalmente la gripe, dolores de estómago, dolores de panza e infecciones.

Palabras-Clave: Conocimiento Tradicional. Etnobotánica. Plantas Medicinales. 


\begin{abstract}
This ethnobotanical study investigated the traditional knowledge on medicinal plants in Sete Saltos de Baixo, a community situated in the district of Itaiacoca, Ponta Grossa - Paraná State. The research included participatory techniques such as interviews in addition to collecting species with community residents for later scientific identification. It were recorded 51 ethnospecies identified by residents as having medicinal use. The taxa most cited belongs to the Asteraceae and Lauraceae families, which, found in back yards. The most commonly used parts of plants was the leaf whereas the most common form of preparation was tea, mainly to prevent flu, stomachaches and infections.
\end{abstract}

Keywords: Traditional Knowledge. Ethnobotany. Medicinal Plant.

\title{
INTRODUÇÃO
}

Os Faxinais paranaenses são remanescentes de um antigo modo de vida no Brasil. Sua formação espacial resulta na configuração de paisagens que integram em diferentes níveis de sustentabilidade socioambiental, o ecossistema Floresta com Araucária às pequenas comunidades de agricultores familiares que manejam coletivamente os recursos naturais. (FLORIANI et al., 2011).

Tal forma de organização e produção camponesa tradicional é encontrada na região Centro-Sul do Paraná, caracterizada por apresentar dois subsistemas: o "criadouro comunitário", local de uso comum, onde se encontram as residências, animais criados à solta e também onde é feita a extração de erva mate e a retirada de madeira de forma sustentável; e a "terra de plantar", em que se desenvolvem as atividades agrícolas, cujas propriedades são de uso particular, predominando o cultivo de produtos para subsistência como milho, feijão, mandioca e outros (LÖWEN-SAHR, 2005).

A organização social das comunidades tradicionais reflete os valores e os conhecimentos que estas populações possuem acerca da natureza, as quais através de sua forma de olhar os ciclos e o conhecimento das especificidades de muitas espécies do ecossistema local fazem com que colaborem para a manutenção das espécies (TOLEDO; BARRERA-BASSOLS, 2009).

As populações tradicionais usam recursos naturais para a sobrevivência, utilizandoos "de diversas formas: medicinal, alimentar, madeira, etc" (STRACHULSKI; FLORIANI, 2013, p. 136) e os elementos que configuram a paisagem local não são apenas resultado de um uso coletivo da paisagem, mas sim resultado de ações comuns e da busca de uma qualidade de vida comunitária.

Muitas comunidades desenvolveram técnicas de manejo as quais proporcionam o prover de suas necessidades, sem esgotar os "recursos" dos quais dependem para sobreviver e assim causando danos "mínimos" a natureza. As pessoas são agentes responsáveis pela alteração da paisagem, mas, não somente de forma negativa. Desta forma, os estudos etnobotânicos vem mostrando os benefícios das práticas do manejo vegetal. (ALBUQUERQUE; ANDRADE, 2002). Segundo Albuquerque e Andrade (2002, 
p.275) "Os seres humanos agem como agente seletivo para plantas, alterando ciclos de vida, padrões de mortalidade, reprodução e sobrevivência de suas populações, bem como modificando e tirando vantagens das defesas químicas para seu benefício".

Não obstante, conforme Floriani et al. (2011), atualmente, os faxinais buscam adaptar-se aos imperativos da lógica de mercado, à pressão fundiária e à ausência de políticas públicas de desenvolvimento local específicas para a realidade socioambiental desses territórios, transformando, para tanto, sua organização socioespacial. Nas palavras dos autores:

Temos, portanto, que a racionalização do espaço e o projeto modernizador do mundo rural têm derivado não somente na perda de qualidade dos atributos biofísicos da paisagem e na pauperização e/ou expulsão das famílias do espaço rural, mas transformaram (em diferentes graus de metamorfose) as expressões identitárias da organização cultural das comunidades rurais. Tal transformação tem resultado na perda progressiva da agrobiodiversidade - fruto das interações coevolutivas desses grupos com o ecossistema florestal - sintetizada em um corpo de saberes e práticas que configuram a cosmovisão dessas comunidades tradicionais. (FLORIANI et al., 2011, p. 223).

Nesse contexto de crises e rupturas dos territórios tradicionais provocado pelo projeto modernizador do mundo rural, são questionados o paradigma científico hegemônico, fazendo emergir desse contexto reflexivo as abordagens científicas alternativas de compreensão das complexas realidades socioterritoriais rurais. Tais abordagens, derivadas do aporte interdisciplinar das ciências sociais e humanas (antropologia, sociologia, geografia) com as ciências da natureza, seriam capazes de religar as culturas com suas naturezas, colocando em um mesmo prisma hermenêutico os saberes científicos e locais de natureza.

Assim, as etnociências passam por um novo sentido ao fornecer subsídios epistemológicos que permitam a convivência em um mesmo plano hermenêutico das formas de interpretação das múltiplas dimensões da realidade socioambiental, a partir da instauração do que Bruno Latour chamaria de uma antropologia simétrica, a partir da qual:

[...] os modernos pensam que só conseguiram tal expansão por terem separado cuidadosamente a natureza e a sociedade (e colocado Deus entre parênteses). [ ] esse dilema permaneceria sem solução caso a antropologia não nos houvesse acostumado, há muito tempo, a tratar sem crises e sem crítica o tecido inteiriço das naturezas-culturas. Contudo, a antropologia simétrica permitiria ao etnólogo] escrever na mesma monografia, a definição das forças presentes, a repartição dos poderes entre humanos, deuses e não-humanos, os procedimentos de consensualização, os laços entre a religião e os poderes, os ancestrais, a cosmologia, o direito à propriedade e as taxonomias de plantas e vegetais. (LATOUR, 1994, p. 20 e 46).

Aplicam-se etnociências a todas as pesquisas etnológicas ou interdisciplinares, na interface das ciências do homem e da vida. A etnoecologia pode ser definida como percepções indígenas das divisões 'naturais' no mundo biológico e das relações planta- 
animal-homem dentro de cada divisão. Essas categorias ecológicas, cognitivamente definidas, não existem isoladamente; portanto, a etnoecologia deve também lidar com as percepções das inter-relações entre as divisões naturais. (POSEY, 1986; ROUÉ, 1997).

Para a UNESCO (2014), os saberes locais ou indígenas se referem a

[...] the cumulative and complex bodies of knowledge, know-how, practices and representations that are maintained and developed by people with extended histories of interactions with the natural environment. These cognitive systems are part of a complex that also includes language, attachment to place, spirituality and worldview. Many different terms are used to refer to this knowledge.

As etnociências, para Enrique Leff (2000):

[...] configuram-se no campo de estudo das relações entre os diferentes grupos étnicos e culturais com seu meio vegetal. Permitem revalorizar e recuperar um arsenal de conhecimentos práticos, capazes de se inserir como "matéria-prima elaborada" na produção de conhecimentos científicos sobre a produtividade dos ecossistemas, sobre o aproveitamento dos seus recursos [...]. (LEFF, 2000, p. 111).

Assim, a etnobotânica compreende "o estudo das sociedades humanas, passadas e presentes, e suas interações ecológicas, genéticas, evolutivas, simbólicas e culturais com as plantas". (FONSECA-KRUEL; PEIXOTO 2004, p. 177).

Segundo Diegues (2005, p.42) “os estudos da etnobotânica são os que apresentam maior número de trabalhos relacionados à utilização de plantas como remédios pelas comunidades". Para Freitas (2009, p. 24) a etnobotânica aparece como "um dos caminhos alternativos que mais evolui para a descoberta de produtos naturais bioativos", obtendo informações sobre a utilização sustentável dessas espécies junto às comunidades tradicionais. Assim, as técnicas utilizadas por essas comunidades muitas vezes se mostram mais eficazes do que algumas desenvolvidas por cientistas, pois as mesmas derivam do conhecimento da biodiversidade dos ecossistemas em que vivem e "estão adaptadas às condições locais de clima, solo, vegetação etc." (ALBUQUERQUE; ANDRADE, 2002, p.274).

Para Diegues e Arruda (2001, p.11), “as espécies são objeto de conhecimento, de domesticação e uso, fonte de inspiração para mitos e rituais das sociedades tradicionais, e vistas como mercadoria nas sociedades modernas". O homem descobriu nas plantas propriedades capaz de curar enfermidades, utilizadas com ritos por um sistema de crenças, não apenas pelas suas propriedades curativas, mas também com uma simbologia, advinda culturalmente. (ARRUDA CAMARGO, 2005/2006). A escolha de técnicas e tratamento do corpo está relacionada à espiritualidade e afetividade, aplicando conhecimentos empíricos e terapêuticos os quais incluem de forma variada a biodiversidade local, tratando o corpo como um todo, o que difere da medicina moderna a qual compartimenta o corpo para tratamento das enfermidades. (OLIVEIRA; BARTHOLO JUNIOR, 2008).

Em relação ao estudo de etnomedicinais o que se percebe em várias regiões do Brasil é que além de fazer parte do conhecimento e da cultura local, esses saberes vêm 
sendo difundidos principalmente devido às dificuldades de acesso a hospitais e postos de saúde ou a falta de recursos para a compra do medicamento industrializado. (VEIGA JUNIOR, 2008). Enfatizam Oliveira e Bartholo Junior (2008, p. 2) que em áreas “desassistidas" por "políticas públicas", as populações apresentam formas características de cuidar da saúde e muitas vezes seus costumes são transmitidos e "organizados em forma de narrativas míticas, imaginárias ou religiosas".

Conforme Roué (1997), a Organização Mundial da Saúde teria sido a primeira a reconhecer "os médicos tradicionais", durante a declaração de Alma-Ata em 1978, uma vez que que ela se deu conta de sua incapacidade de fornecer ajuda médica aos países em desenvolvimento. Segundo estimativas da OMS de 1978, 80\% da população mundial usava principalmente plantas medicinais populares para suprir suas necessidades de assistência médica primária. (ROUÉ, 1997; ALMEIDA, 2003).

O Brasil, conforme Almeida (2003), demorou a adotar a política para os medicamentos fitoterápicos e plantas in natura, bem como uma legislação específica para seu comércio. Apenas em 1989, o Ministério de Saúde lança a portaria nº 212 de 1989, definindo o estudo das plantas medicinais como prioridade.

Com o objetivo de desenvolver o setor de fitoterápicos no Brasil, no ano de 2006 foi aprovada a Política Nacional de Plantas Medicinais e Fitoterápicos, que veio a definir o uso de plantas medicinais no atendimento público à saúde, visando um uso racional e "respeitando desde o conhecimento tradicional até o uso da biodiversidade do país". (SANTOS et al., 2011, p. 490). Esta Política foi a base para o que depois através da Portaria Interministerial $\mathrm{n}^{\mathrm{o}}$ 2960, de 9 de dezembro de 2008, passou a ser o Programa Nacional de Plantas Medicinais e Fitoterápicos. (TEIXEIRA et al., 2012).

A implantação do Programa Nacional de Plantas Medicinais e Fitoterápicos busca:

[...] a melhoria do acesso da população aos medicamentos, à inclusão social e regional, ao desenvolvimento industrial e tecnológico, além do uso sustentável da biodiversidade brasileira e da valorização, valoração e preservação do conhecimento tradicional associado das comunidades tradicionais e indígenas. (BRASIL, 2006).

Em geral é comum encontrar nos quintais agroflorestais plantas nativas e exóticas que apresentam como principal função o uso como remédios. Segundo Santos e Fajardo (2008, p. 2), "no Brasil, esse cultivo em áreas rurais e urbanas de espécies nativas e exóticas se deve ao desmatamento e a exploração predatória dos recursos vegetais que resultaram na perda dessa rica farmácia natural".

O Paraná através dos seus ciclos econômicos e mudanças no seu uso do espaço vem sofrendo intenso desmatamento e Löwen Sahr (2005) destaca a importância da cultura das comunidades tradicionais na relação com a natureza, pois mesmo sofrendo pressão e influências desses processos, as comunidades faxinais conservaram a cobertura vegetal natural. Todavia, cabe ressaltar a pressão econômica que vem sendo exercida sobre essas comunidades e a transformação nos processos produtivos, ameaça à flora e aos saberes e práticas realizados nas comunidades tradicionais, o que faz com que estudos da etnobotânica venham a colaborar ao registrar a cultura desses povos. 
Lima (2011, p.16, p. 105) destaca a Mata de Araucária preservada como um dos "traços específicos do Faxinal" e assegura como sendo "evidente que a manutenção desse sistema tem contribuído para a grande extensão de mata preservada existente." Para Floriani et al. (2011, p.2) o faxinal é um sistema que pode ser considerado de uso sustentável pois utiliza a área e ao mesmo tempo mantém o ecossistema da Floresta de Araucária, sendo "os últimos remanescentes expressivos de Floresta Ombrófila Mista da região, merecendo o status de unidades de conservação estaduais". Do mesmo modo Silva e Carvalho (2011) também verificaram que os faxinalenses apresentam uma relação harmoniosa com o ecossistema em que vivem, pois mantém a vegetação natural da região que é a Mata com Araucária.

A respeito da qualidade das florestas encontradas nos Faxinais, Struminski e Strachulski (2011) destacam os problemas da exploração seletiva em florestas, apontando que os Faxinais não são sustentáveis no aspecto de conservação dos fragmentos da Floresta Ombrófila Mista, pois apresentam degradação e ausência de algumas espécies. Moro e Lima (2012, p.88 e 89), ao realizar o levantamento fitossociológico no Faxinal Sete Saltos de Baixo, constataram:

[...] uma Floresta Ombrófila Mista Montana que se enquadra na tipologia de Floresta Antropizada por Sistemas Agrosilvopastoris. A ausência de espécies típicas em faxinais, como Araucaria angustifolia e Ilex paraguariensis, deve-se à retirada seletiva de madeira no passado e à forma de manejo, com a presença de animais que altera a dinâmica da vegetação [...] Por outro lado, podem ser observadas espécies madeireiras de maior valor econômico como canela-guaicá (Ocotea puberula), canela-sassafrás (Ocotea odorifera) e cedro (Cedrela fissilis). (MORO; LIMA, 2012, p. 88 -89).

No entanto, outras pesquisas mostram o quão importante são os saberes locais para a manutenção da biodiversidade. Constatando que as maiores áreas preservadas ainda se encontram em locais onde vivem as comunidades tradicionais e que estas dependem da natureza para sobrevivência. (ARRUDA, 1999)

Este estudo buscou investigar os conhecimentos tradicionais sobre o uso de plantas medicinais na Comunidade Faxinal Sete Saltos de Baixo localizada no distrito de Itaiacoca, em Ponta Grossa (PR). O Faxinal em questão mantém alguns costumes relativos à flora local, como o conhecimento e utilização de várias espécies vegetais nativas da região. Além de que, possuem práticas que reforçam os laços de solidariedade como a troca de plantas medicinais e a transmissão do conhecimento fitoterápico. A comunidade ao socializar os conhecimentos a respeito da fauna e da flora do ecossistema em que vivem, perpetuam a união e o respeito, presentes também nas tradições dos festejos religiosos, momentos onde a comunidade se reúne, ensaiam danças e preparam alimentos para confraternização. 


\section{CARACTERIZAÇÃO DA ÁREA DE ESTUDO}

A comunidade faxinalense Sete Saltos de Baixo (Figura 1) pertence ao município de Ponta Grossa, localizada a "sudeste da bacia do Rio Sete Saltos no distrito de Itaiacoca, a aproximadamente $45 \mathrm{~km}$ da área urbana deste município (FERREIRA, 2009, p.14-18), estando sob o "Planalto Dissecado do Alto Ribeira." (OKA-FIORI; SANTOS, 2006, p. 48).

Figura 1 - Localização da área de estudo

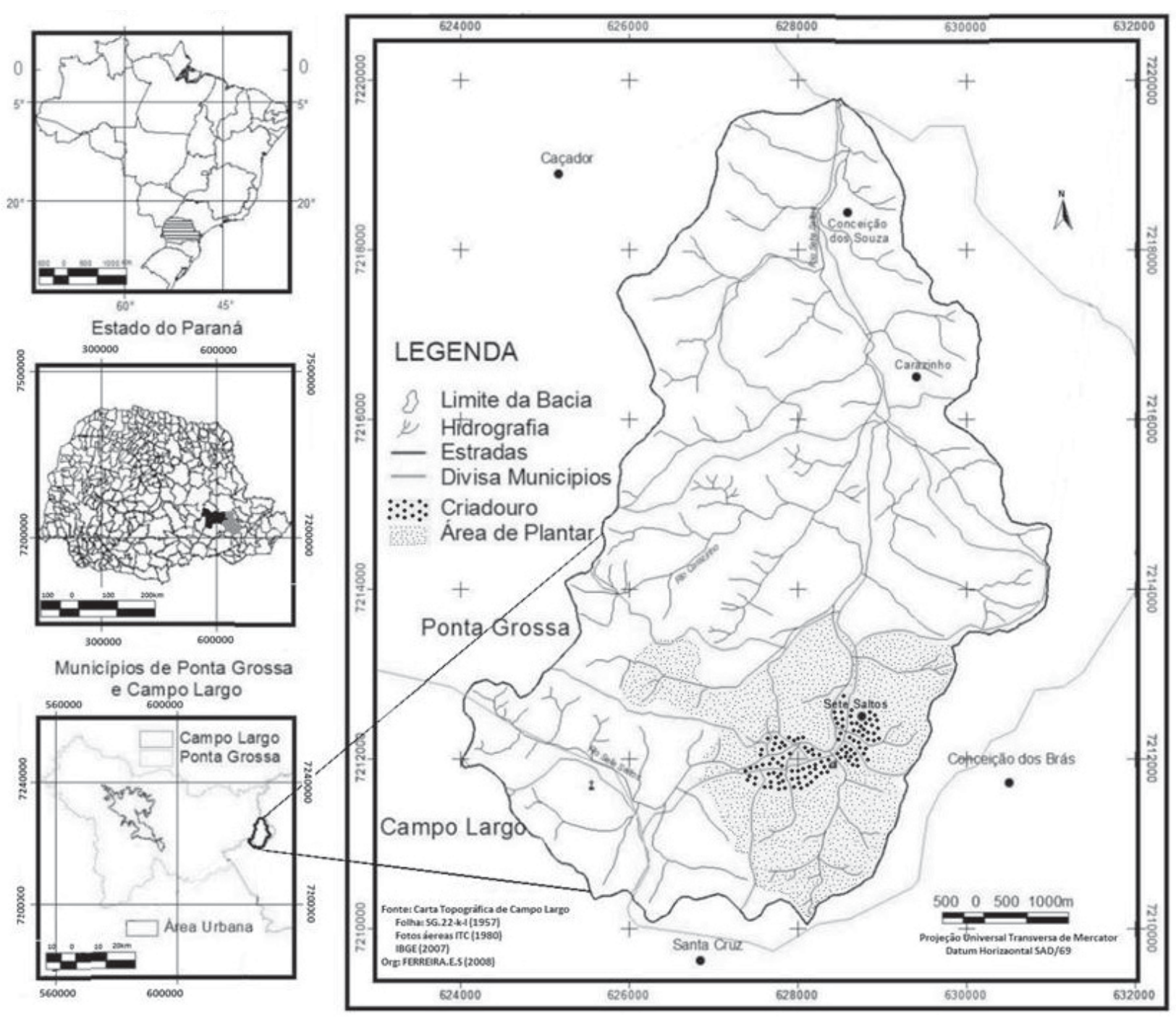

Fonte: Adaptado de FERREIRA (2009)

A história de Itaiacoca inicia-se com o povoamento dos Campos Gerais quando as "famílias nobres" paulistas adquirem as terras da sesmaria de Itaiacoca para a criação de gado. (SILVA, 2008). Já com a divisão destas terras entre familiares, há o surgimento de grandes latifúndios, que posteriormente fragmentaram-se com o abandono da terra pelos latifundiários e dão origem a várias localidades, dentre elas Sete Saltos de Baixo. (SILVA, 2008). 
No início do século XX com a descoberta de fontes de minério na região, e mais tarde a vinda de madeireiras os agricultores locais passam a buscar emprego nestas novas áreas de trabalho, diminui o tempo disponível para a prática agrícola e outras atividades de subsistência. Porém algumas localidades mantiveram suas tradições caboclas de subsistência, além das festas e bailes. (SILVA, 2008).

O faxinal está sob duas formações vegetais que recobrem a região: Floresta Ombrófila Mista Montana, encontrada em áreas de "clima temperado úmido de altitude", destacando-se a Araucaria angustifolia que atinge em média “30 metros de altura”. (CARMO et al., 2007, p.100-101) e Floresta Ombrófila Mista Aluvial, encontrada próxima aos rios, sendo também chamada de "mata ripária", destacando-se em seu estrato superior espécies como: Lithraea molleoides (bugreiro), Ocotea porosa, (imbuia), Cinnamomum sellowianum (canela-raposa), Schinus terebinthifolius (aroeira)" e outras. (CARMO et al., 2007, p.100101).

\section{MATERIAIS E MÉTODOS}

A pesquisa teve início a partir de um levantamento exploratório, que consistiu na primeira aproximação com o universo de pesquisa, no que tange aos aspectos de organização comunitária e demandas reais acerca do tema saúde e plantas medicinais.

Para buscar quais os informantes-chaves (pessoas com conhecimento destacado em relação às plantas medicinais) utilizou-se de técnicas de pesquisa participativa (ALBUQUERQUE et al., 2010), com a realização de uma reunião no início de junho de 2011. O faxinal é composto por aproximadamente 60 famílias, e participaram desta atividade ${ }^{1}$ cinco mulheres e quatro homens na elaboração de um diagnóstico da realidade socioespacial (aspectos físicos e socioeconômicos da comunidade), bem como do corpo de conhecimentos relativos à ecologia, produção e utilização das plantas medicinais, resultando numa troca de informações e conhecimentos entre os participantes da reunião.

Para a atividade foi sugerido que estes se dividissem em dois grupos, um com homens outro com mulheres (Figuras 2 e 3), e que cada grupo desenhasse um mapa de localização de suas moradias em relação à área do Faxinal. A intenção da divisão dos grupos de gêneros se deve à necessidade de entender se existem diferenças nas atividades, representação da paisagem e relação destes com o meio. (FAO, 2011). A reunião se caracterizou por um momento de interação com a comunidade e incentivo ao surgimento de um ambiente aberto ao diálogo, possibilitando a identificação dos informantes com maior conhecimento das espécies medicinais, através da repetição da recomendação feita por estes acerca das espécies da flora local.

Foram então entregues cartolinas e solicitado para que os moradores desenhassem um mapa do Faxinal.

\footnotetext{
${ }^{1}$ Atividade realizada com os alunos do Mestrado em Gestão do Território (UEPG), durante a disciplina Diagnóstico e Gestão Participativa de Recursos Naturais, Turma VI, sob responsabilidade do Dr. Nicolas Floriani, em 2011.
} 
Figura 2 - Homens desenhando o mapa na cartografia participativa no Faxinal Sete Saltos de Baixo, Ponta Grossa, PR.

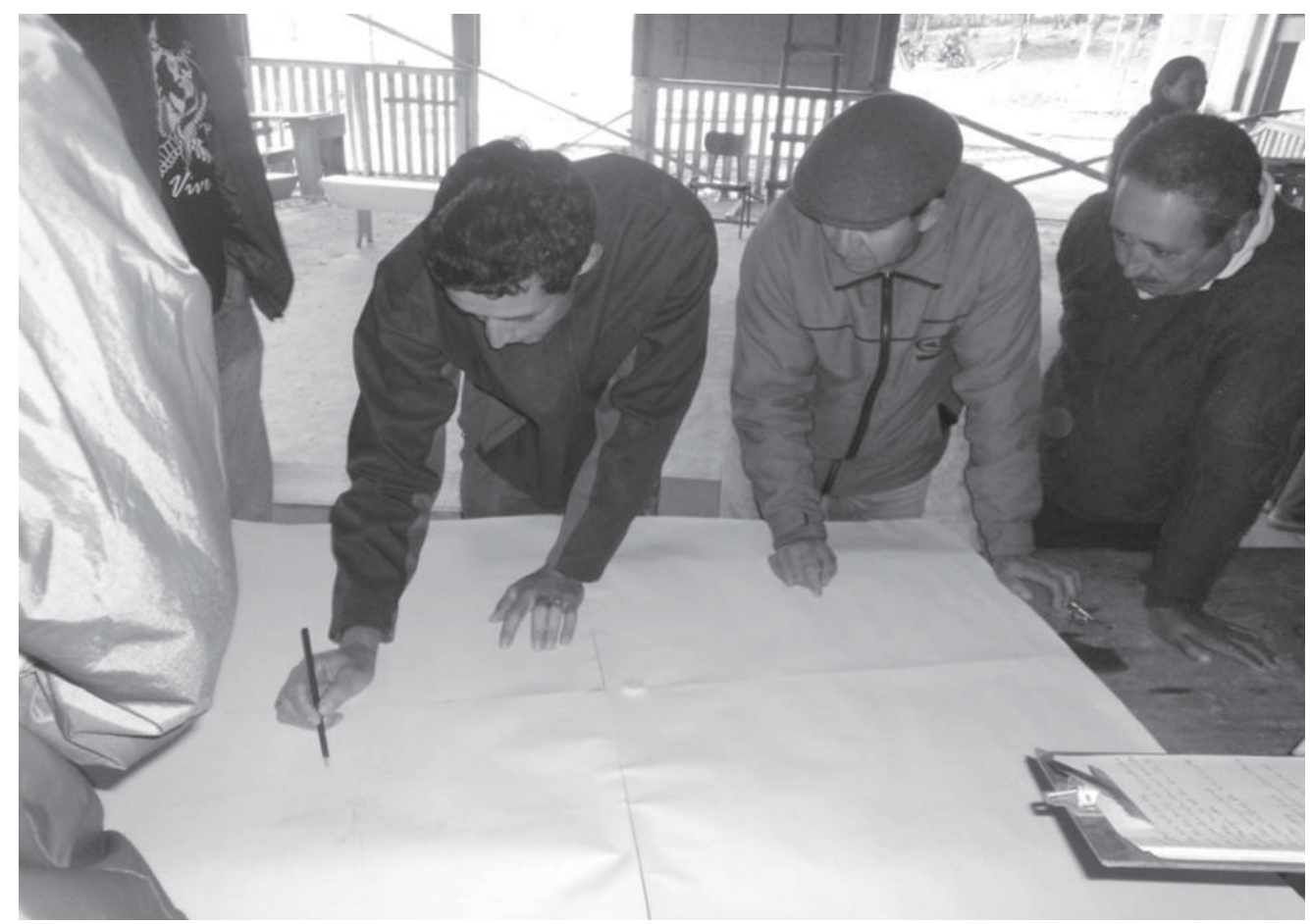

Fonte: UEPG, TURMA VI (2011).

Figura 3 - Mulheres desenhando o mapa na cartografia participativa no Faxinal Sete Saltos de Baixo, Ponta Grossa, PR.

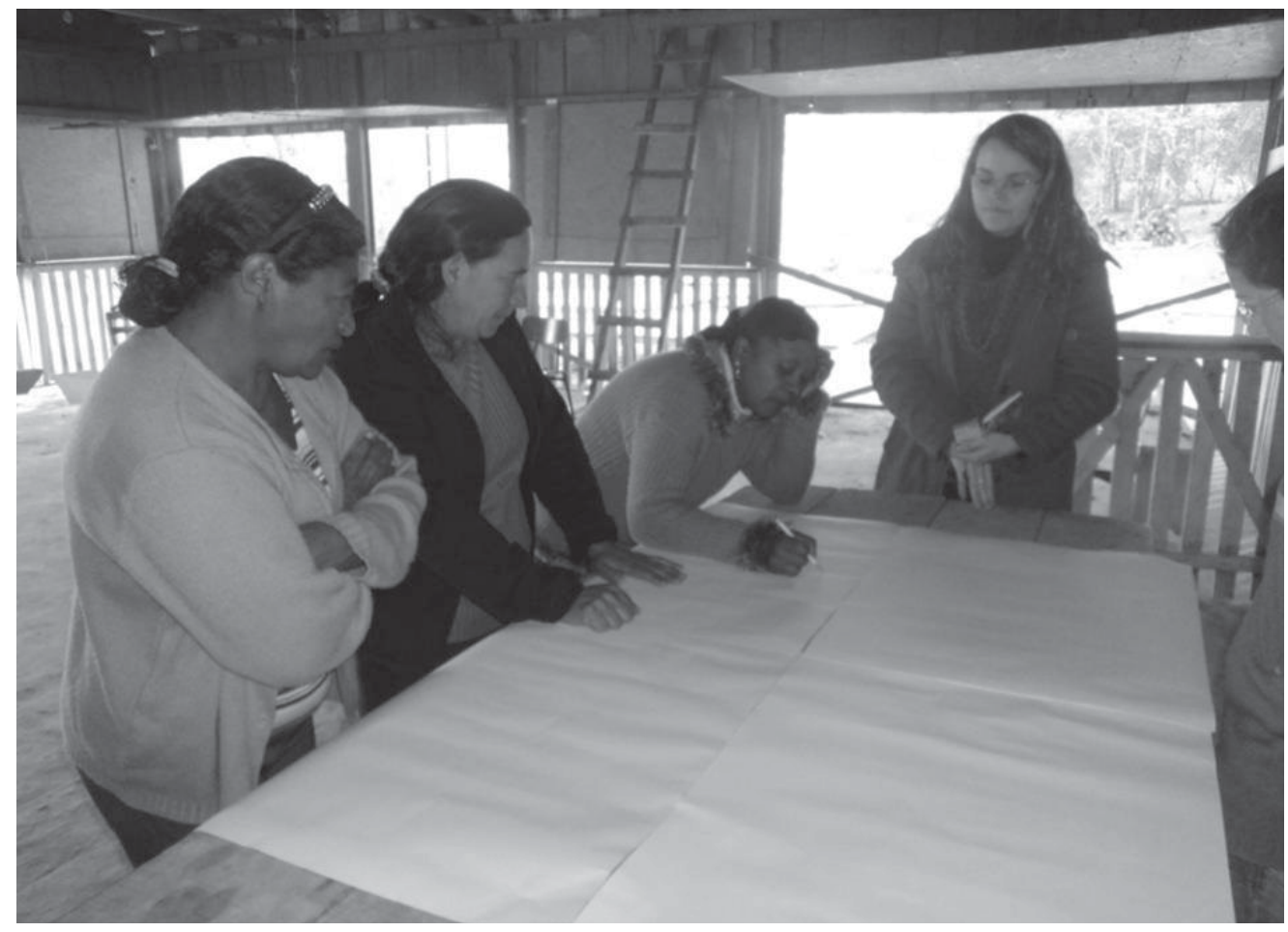

Fonte : UEPG, TURMA VI (2011). 
O mapa das mulheres apresenta detalhes que estão relacionados ao seu dia-a-dia, assim detalham mais as casas e o que há em volta delas, o quintal. Já o mapa dos homens, que geralmente desempenham atividades em locais mais distantes e as mais pesadas, como o conserto das cercas que delimitam o criadouro, esboça os caminhos, espécies de árvores, delimita o espaço que é percorrido pelos moradores da comunidade no seu diaa-dia.

Com a identificação dos informantes-chaves, foram efetuadas entrevistas semiestruturadas (ALBUQUERQUE et al., 2010) com cinco pessoas (dois homens e três mulheres), visando compreender os aspectos da classificação e nomenclatura vernaculares das plantas. Também se utilizou como critério o tempo em que residem na comunidade (mais de 15 anos), a prática de ritos, benzeduras, rezas, associada ao uso de plantas, e o ato de compartilhar seus conhecimentos com os demais membros da comunidade.

As entrevistas ocorreram nas residências dos informantes, onde buscou-se estabelecer um ambiente no qual a pessoa se sentisse a vontade para conversar, sendo que em algumas casas essas entrevistas ocorreram em meio às "rodas de chimarrão", assim, auxiliaram na identificação das espécies vegetais e seus usos. A identidade cabocla é expressa através dos "causos", relatos das pessoas mais velhas, que transmitem seus costumes e crenças aos faxinalenses mais jovens. O chimarrão é um hábito da cultura cabocla repassado através das gerações, presente em vários povos tradicionais paranaenses. (THOMÉ, 2006).

Após a entrevista, ainda em junho de 2011, foi solicitado que o entrevistado localizasse as plantas que citou através da "turnê guiada", ou seja, de uma caminhada com o entrevistado até o local onde ele busca a planta para uso medicinal. Segundo Albuquerque (2010):

Trata-se de um método utilizado para trabalhar em campo que, normalmente, necessita de um mateiro ou guia local (membro da comunidade reconhecidamente hábil em deslocar-se na vegetação da região e com um rico conhecimento da flora local) ou alguns dos principais informantes escolhidos nas comunidades estudadas. (ALBUQUEQUE et al., 2010, p.49).

Em duas das entrevistas estavam presentes os cônjuges, mas a turnê guiada contou com a presença de mulheres, que conduziram a coleta de plantas medicinais herbáceas, próximas a casa (hortas-quintais, criadouro), enquanto os homens auxiliaram na coleta das espécies arbóreas e plantas que se encontravam mais distantes (mato, terra de plantar). Foram coletados ramos, folhas e flores.

Por fim, as espécies vegetais coletadas foram levadas para identificação no Herbário da Universidade Estadual de Ponta Grossa, podendo-se relacionar os nomes popular e científico das espécies. A grafia dos táxons e dos autores e a origem das espécies foram obtidas por consulta à Lista de Espécies medicinais, aromáticas e condimentares USP e Lista de Espécies da Flora do Brasil (2011). 


\section{RESULTADOS E DISCUSSÃO}

Através das informações coletadas sobre o uso de plantas medicinais na comunidade Faxinal Sete Saltos de Baixo, foi possível evidenciar que a população utiliza as plantas medicinais e que não apenas convive com a biodiversidade local, que na visão de Diegues:

[..] nomeiam e classificam as espécies vivas segundo suas próprias categorias e nomes [...] e essa diversidade da vida não é vista como 'recurso natural', mas sim como um conjunto de seres vivos que tem um valor de uso, um valor simbólico, integrado numa complexa cosmologia. (DIEGUES 2004, p.16).

Por meio da Cartografia Participativa obteve-se resultados relativos à classificação e localização das plantas utilizadas para fins medicinais no território faxinalense. A classificação local das plantas envolve tanto a nomenclatura (forma de vida e uso) quanto a localização (representação espacial da comunidade).

A pesquisa registrou um total de 51 etnoespécies (Quadro 1) apontadas pelos moradores como possuindo uso medicinal. As espécies mais citadas foram das famílias Asteraceae e Lauraceae, contudo apresentou-se grande diversidade de famílias.

Quadro 1 - Espécies medicinais citadas pelos moradores da comunidade Faxinal Sete Saltos de Baixo, Ponta Grossa -PR

\begin{tabular}{|c|c|c|c|c|c|c|}
\hline $\begin{array}{l}\text { Nome } \\
\text { popular }\end{array}$ & Família & Nome científico & Origem & $\begin{array}{l}\text { Parte } \\
\text { utilizada }\end{array}$ & $\begin{array}{l}\text { Forma de } \\
\text { uso }\end{array}$ & Uso \\
\hline Agrião & Brassicaceae & Nasturtium officinalis L. & Naturalizada & folha & Xarope & gripe \\
\hline Alecrim & Lamiaceae & Rosmarinus officinalis L. & Naturalizada & folha & Chá & diarréia e infecção \\
\hline Alevante & Lamiaceae & Mentha spicata L. & Naturalizada & folha & Chá & vermes \\
\hline Alfavaca & Lamiaceae & Oncimum selloi Benth. & Nativa & folha & Chá & rim e gripe \\
\hline Araçá & Myrtaceae & Psidium cattleianum Sabine & Nativa & casca & Chá & câncer \\
\hline Arruda & Rutaceae & Ruta graveolens L. & Naturalizada & folha & Chá & dor de cabeça \\
\hline Badana & Asteraceae & $\begin{array}{l}\text { Arctium minus } \\
\text { (Hill) Bernh }\end{array}$ & Naturalizada & raiz & Chá & $\begin{array}{l}\text { problemas de } \\
\text { sangue }\end{array}$ \\
\hline Boldo & Lamiaceae & Plectranthus barbatus & Naturalizada & folha & Chá & estômago \\
\hline Cabriúva & Fabaceae & Myrocarpus sp. & Nativa & casca & Chá & $\begin{array}{l}\text { ferimentos na pele e } \\
\text { problemas de pele }\end{array}$ \\
\hline Cânfora & Lauraceae & $\begin{array}{l}\text { Cinnamomun camphora } \\
\text { (L.) J. Presl. }\end{array}$ & Cultivada & folha & Chá & estômago \\
\hline Caroba & Bignoniaceae & Jacaranda sp. & Nativa & folha e casca & $\begin{array}{l}\text { Chá e } \\
\text { banho }\end{array}$ & $\begin{array}{l}\text { ferimentos na pele e } \\
\text { problemas de sangue }\end{array}$ \\
\hline Carqueja & Asteraceae & Baccharis crispa Spreng. & Nativa & folha & $\begin{array}{l}\text { Chá e } \\
\text { banho }\end{array}$ & $\begin{array}{l}\text { Emagrecedor } \\
\text { friagem } \\
\text { dor e inchaço (banho) }\end{array}$ \\
\hline Carrapicho & Asteraceae & $\begin{array}{l}\text { Acanthospermum australe } \\
\text { (Loefl.) Kuntze }\end{array}$ & Nativa & folha & Chá & $\operatorname{rim}$ \\
\hline $\begin{array}{l}\text { Chapéu-de- } \\
\text {-couro }\end{array}$ & Alismataceae & $\begin{array}{l}\text { Echinodorus grandiflorus } \\
\text { (Cham. \& Schltr.) Micheli }\end{array}$ & Nativa & folha & $\begin{array}{l}\text { Chá e } \\
\text { chimarrão }\end{array}$ & $\begin{array}{l}\text { infecção, gripe, } \\
\text { infecção do sistema } \\
\text { urinário }\end{array}$ \\
\hline $\begin{array}{l}\text { Cipó-de- } \\
\text {-São-João }\end{array}$ & Bignoniaceae & $\begin{array}{l}\text { Pyrostegia venusta } \\
\text { (Ker Gawl.) Miers }\end{array}$ & Nativa & $\begin{array}{l}\text { Toda planta } \\
\text { (jovem) }\end{array}$ & banho & $\begin{array}{l}\text { infecção do trato } \\
\text { urinário }\end{array}$ \\
\hline
\end{tabular}


continuação

\begin{tabular}{|c|c|c|c|c|c|c|}
\hline $\begin{array}{l}\text { Nome } \\
\text { popular }\end{array}$ & Família & Nome científico & Origem & $\begin{array}{l}\text { Parte } \\
\text { utilizada }\end{array}$ & \begin{tabular}{|l|} 
Forma de \\
uso
\end{tabular} & Uso \\
\hline Coentro & Apiaceae & Coriandrum sativum L. & Naturalizada & \begin{tabular}{|l} 
Folha e \\
semente
\end{tabular} & Chá & $\begin{array}{l}\text { Infecção na garganta } \\
\text { e calmante }\end{array}$ \\
\hline $\begin{array}{l}\text { Copaíba-da- } \\
\text {-horta }\end{array}$ & $\begin{array}{l}\text { Não } \\
\text { identificado }\end{array}$ & Não identificada & $\begin{array}{l}\text { Não } \\
\text { identificada }\end{array}$ & latex & garrafada & câncer \\
\hline $\begin{array}{l}\text { Erva-de- } \\
\text {-bicho }\end{array}$ & Polygonaceae & $\begin{array}{l}\text { Polygonum hydropiperoides } \\
\text { Michx }\end{array}$ & Nativa & folha & banho & hemorróidas \\
\hline $\begin{array}{l}\text { Erva-de- } \\
\text {-lagarto }\end{array}$ & Rubiaceae & Diodia alata Nees \& Mart & Nativa & folha & banho & $\begin{array}{l}\text { Infecção no útero e } \\
\text { problemas genitais }\end{array}$ \\
\hline Erva-doce & Apiaceae & Pimpinella anisum L. & Cultivada & $\begin{array}{l}\text { folha e } \\
\text { semente }\end{array}$ & Chá & $\begin{array}{l}\text { Bronquite, gripe e } \\
\text { problemas intestinais }\end{array}$ \\
\hline Erva-tostão & Nyctaginaceae & Boerhavia diffusa L. & Nativa & folha & \begin{tabular}{|l|l} 
chá e \\
chimarrão
\end{tabular} & $\operatorname{rim}$ \\
\hline Fel-da-terra & Gentinaceae & Centaurium erythraea Rafn. & Naturalizada & folha e caule & Chá & estômago \\
\hline Guabiroba & Myrtaceae & $\begin{array}{l}\text { Campomanesia xanthocarpa } \\
\text { (Mart.) O.Berg }\end{array}$ & Nativa & folha & banho & dor reumática \\
\hline Gengibre & Zingiberaceae & Zingiber officinale Roscoe & Cultivada & raiz & $\begin{array}{l}\text { chimarrão } \\
\text { e pastilha }\end{array}$ & resfriado e gripe \\
\hline Guaco & Asteraceae & Mikania glomerata Spreng. & Nativa & folha & \begin{tabular}{|l|l|}
$\begin{array}{l}\text { chá e } \\
\text { chimarrão }\end{array}$ \\
\end{tabular} & gripe e tosse \\
\hline Hortelã & Labiatae & Mentha piperita L. & Cultivada & folha & Chá & Vermes e diarreia \\
\hline $\begin{array}{l}\text { Hortelã- } \\
\text {-preto }\end{array}$ & Labiatae & Mentha arvensis L. & Cultivada & folha & Chá & Vermes e tosse \\
\hline Ipê-roxo & Bignoniaceae & $\begin{array}{l}\text { Handroanthus impetiginosus } \\
\text { (Mart. ex DC.) Mattos }\end{array}$ & Nativa & casca & Chá & câncer \\
\hline Laranjeira & Rutaceae & Citrus sinensis L. & Cultivada & folha ou casca & Chá & gripe e resfriado \\
\hline Louro & Lauraceae & Laurus nobilis L. & Cultivada & folha & \begin{tabular}{|l|l} 
chá e \\
chimarrão
\end{tabular} & calmante \\
\hline Losma & Asteraceae & Artemisia absinthium L. & Nativa & folha & \begin{tabular}{|l|l} 
chá e \\
macerada
\end{tabular} & Estômago e enjoo \\
\hline $\begin{array}{l}\text { Maçanilha/ } \\
\text { Camomila }\end{array}$ & Asteraceae & Matricaria chamomilla L. & Naturalizada & Flor & \begin{tabular}{|l|} 
Chá e \\
Chimarrão
\end{tabular} & $\begin{array}{l}\text { Calmante, coração, } \\
\text { bom para tudo }\end{array}$ \\
\hline Manjerona & Lamiaceae & Origanum majorana L. & Naturalizada & folha & \begin{tabular}{|l} 
Chá e \\
xarope
\end{tabular} & resfriado e gripe \\
\hline Marcela & Asteraceae & Achyrocline satureioides (Lam.) DC. & Nativa & flor & Chá & $\begin{array}{l}\text { gripe dor no peito e } \\
\text { estômago }\end{array}$ \\
\hline Milome & Aristolochiaceae & $\begin{array}{l}\text { Aristolochia cymbifera Mart. \& } \\
\text { Zucc. }\end{array}$ & Nativa & folha e cipó & $\begin{array}{l}\text { Chá e } \\
\text { banho }\end{array}$ & $\begin{array}{l}\text { Estômago, resfriado } \\
\text { e dor nas articulações } \\
\text { (banho) }\end{array}$ \\
\hline Mimosa & Rutaceae & Citrus reticulata Blanco & Naturalizada & folha & Chá & calmante \\
\hline $\begin{array}{l}\text { Pata-de- } \\
\text {-cavalo }\end{array}$ & Cyperaceae & Cyperus rotundus L. & Nativa & $\begin{array}{l}\text { toda a planta } \\
\text { (jovem) }\end{array}$ & Chá & $\begin{array}{l}\text { regulariza } \\
\text { ciclo menstrual }\end{array}$ \\
\hline $\begin{array}{l}\text { Pau-de- } \\
\text {-andrade }\end{array}$ & Lauraceae & Persea pyrifolia Nees \& Mart. & Nativa & casca & banho & $\begin{array}{l}\text { ferimentos na pele e } \\
\text { problemas de pele }\end{array}$ \\
\hline $\begin{array}{l}\text { Pau-de- } \\
\text {-quina }\end{array}$ & Simaroubaceae & Quassia amara L. & Nativa & folha & Chá & diarreia e infecção \\
\hline $\begin{array}{l}\text { Pau-de- } \\
\text {-raposa }\end{array}$ & Lauraceae & $\begin{array}{l}\text { Cinnamomum stenophyllum } \\
\text { (Meisn.) Vattimo-Gil }\end{array}$ & Nativa & casca & Chá & $\begin{array}{l}\text { câncer, diabete e } \\
\text { ferimentos }\end{array}$ \\
\hline Picão-preto & Asteraceae & Bidens pilosa L. & Naturalizada & folha & banho & Infecção e resfriados \\
\hline Pitangueira & Myrtaceae & Eugenia uniflora L. & Nativa & casca & Chá & câncer \\
\hline Poejo & Lamiaceae & Mentha pulegium L. & Naturalizada & folha & \begin{tabular}{|l|}
$\begin{array}{l}\text { Chá e } \\
\text { xarope }\end{array}$ \\
\end{tabular} & gripe e tosse \\
\hline $\begin{array}{l}\text { Quebra- } \\
\text {-pedra }\end{array}$ & Plyllanthaceae & Phyllanthus niruri L. & Naturalizada & folha & Chá & infecção urinária \\
\hline
\end{tabular}


conclusão

\begin{tabular}{|c|c|c|c|c|c|c|}
\hline $\begin{array}{l}\text { Nome } \\
\text { popular }\end{array}$ & Família & Nome científico & Origem & $\begin{array}{l}\text { Parte } \\
\text { utilizada }\end{array}$ & $\begin{array}{l}\text { Forma de } \\
\text { uso }\end{array}$ & Uso \\
\hline $\begin{array}{l}\text { Sete- } \\
\text { sangrias }\end{array}$ & Lythraceae & Cuphea calophylla Cham. \& Schltdl. & Nativa & $\begin{array}{l}\text { raiz ou toda } \\
\text { planta }\end{array}$ & Chá & $\begin{array}{l}\text { Infecção do trato } \\
\text { urinário }\end{array}$ \\
\hline $\begin{array}{l}\text { Sordinha/ } \\
\text { Chorão }\end{array}$ & Cactaceae & Rhipsalis sp & Nativa & toda planta & Emplasto & $\begin{array}{l}\text { machucaduras e } \\
\text { quebraduras }\end{array}$ \\
\hline Tanchagem & Plantaginaceae & Plantago sp & Nativa & folha & Chá & infecções diversas \\
\hline $\begin{array}{l}\text { Unha-de- } \\
\text {-gato }\end{array}$ & Rubiaceae & $\begin{array}{l}\text { Uncaria tomentosa (Willd. ex } \\
\text { Roem. \& Schult.) DC. }\end{array}$ & Nativa & cipó & chá & $\begin{array}{l}\text { dor na coluna e } \\
\text { vesícula }\end{array}$ \\
\hline Urtiga-brava & Urticaceae & $\begin{array}{l}\text { Urera baccifera (L.) Gaudich. ex } \\
\text { Wedd. }\end{array}$ & Nativa & raiz & $\begin{array}{l}\text { chá, } \\
\text { chimarrão } \\
\text { e banho }\end{array}$ & $\begin{array}{l}\text { Estomago } \\
\text { Hemorroidas } \\
\text { dor na coluna }\end{array}$ \\
\hline Vassourinha & Asteraceae & Baccharis sp & Nativa & $\begin{array}{l}\text { toda planta } \\
\text { (jovem) }\end{array}$ & Chá & $\begin{array}{l}\text { regulariza o ciclo } \\
\text { menstrual }\end{array}$ \\
\hline
\end{tabular}

Fonte: STANISKI, 2011.

Verificou-se que os moradores da comunidade utilizam as plantas no seu dia-adia e a parte mais utilizada destas é a folha, na forma de chá, sendo as outras partes mais citadas foram casca, raiz, inteira, flor, semente, cipó e látex (Figura 4). Esse resultado foi semelhante ao obtido por Amorozo (2002, p.193).

São empregados também xarope (3 citações), banho (10 citações), garrafada (1 citação), macerado (1 citação), diluição do óleo essencial (1 citação) e utilização no chimarrão (7 citações). Não houve relatos de uso de frutos para a cura de enfermidades.

Figura 4 - Partes utilizadas da planta para o preparo medicinal na comunidade Faxinal Sete Saltos de Baixo, Ponta Grossa, PR.

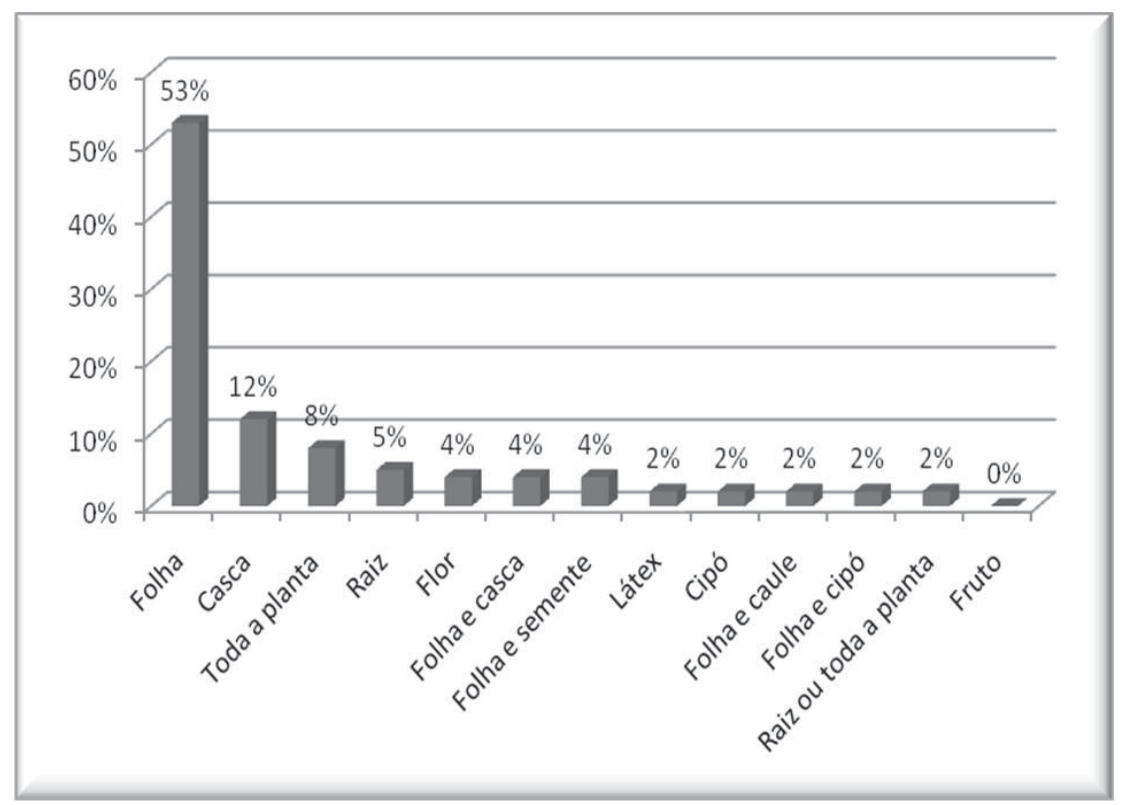

Fonte: Staniski, 2011.

Já em relação aos ambientes em que foram encontradas as plantas destacam-se as hortas-quintais e estradas, locais próximos das casas dos faxinalenses. O local da coleta 
das plantas e o uso de uma espécie em detrimento da outra se justifica também pela disponibilidade da mesma na região e pela configuração social da comunidade estudada. (AMOROZO, 2002)

Em vários momentos, durante a entrevista semiestruturada, as plantas mais citadas na fala dos moradores foram a camomila, que segundo as mulheres faxinalenses é boa para todos os problemas, o boldo e o alecrim. Estas plantas são cultivadas em hortaquintais e são espécies de uso comum em várias comunidades no Brasil. (FREITAS, 2009; PAULA; CRUZ-SILVA, 2010).

Além de serem encontradas em horta-quintais as espécies medicinais também podem ser encontradas em pomares no criadouro comunitário (Figura 5), na área de roça (terra de plantar) e no mato (áreas em estágios sucessionais variados), sendo que as ervas são mais encontradas em horta-quintais e as árvores e lianas nas roças e no mato. Dentre as espécies nativas e/ou que se encontram principalmente fora das hortas-quintais, as mais lembradas pelos moradores foram: raiz-de-urtiga-brava, a carqueja, a marcela, erva-de-bicho, o milome e o guaco, sendo que os dois últimos são lianas encontradas na mata e segundo os faxinalenses é necessário percorrer vários quilômetros para coletar. As plantas mais citadas são as mais utilizadas ou as que curam as enfermidades mais recorrentes. Das espécies medicinais encontradas na mata e utilizadas pelos moradores da comunidade destacam-se a cabriúva, a carova e pau-de-raposa.

Figura 5 - Criadouro comunitário onde se localizam as casas e pomares, na comunidade Faxinal Sete Saltos de Baixo, Ponta Grossa, PR

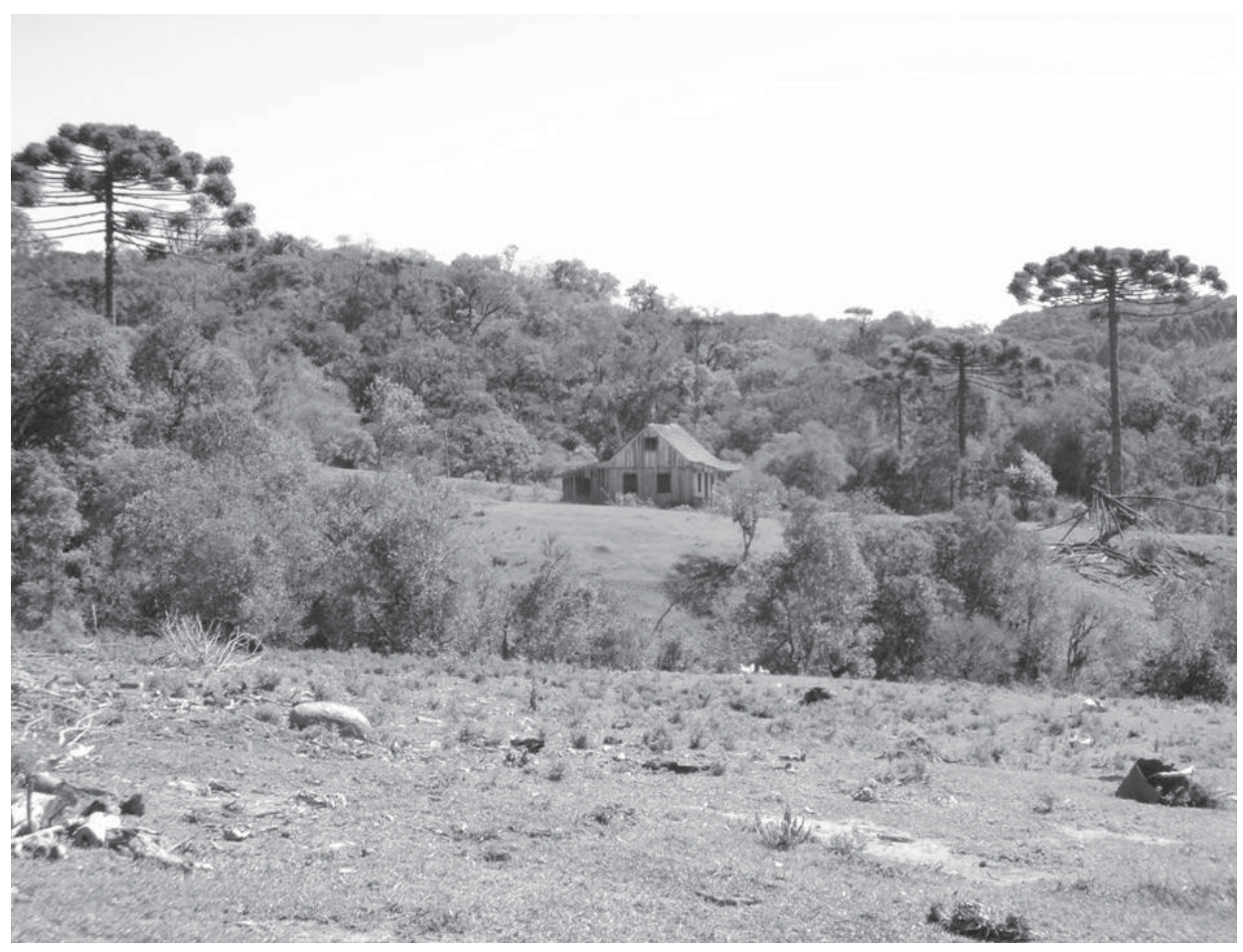

Fonte: Staniski, 2011.

As espécies utilizadas no chimarrão e as demais, em sua maioria, não apresentam contraindicações e seu uso é realizado de forma empírica. Das plantas utilizadas para 
fazer banhos alguns apresentam restrições ou contra indicações como o milome, a folha de gaviroveira, a erva-de-bicho e a carqueja. Segundo os entrevistados, o banho deve ser realizado preferencialmente no período da manhã, pois se acredita que gera melhores resultados, e após este a pessoa deve permanecer em casa por no mínimo dois dias sem sair ao vento, umidade ou frio.

Embora a comunidade faça uso de alguns fármacos químicos junto com as plantas, o uso de fitoterápicos para o tratamento de enfermidades mostra-se eficaz na comunidade, pois permanece no cotidiano das famílias sendo repassado de geração em geração, portanto, ressignificado em práticas medicinais híbridas.

Foram citados 26 problemas tratados com o uso de plantas medicinais, dentre os quais se destacam: gripes, infecções diversas, sistema digestório, sistema nervoso, combate a vermes e trato genital-urinário (Figura 6). Resultados equivalentes são encontrados em outras pesquisas como as de Amoroso (2002) e Giraldi e Hanazaki (2010), cujas espécies medicinais são utilizadas majoritariamente pra tratar de problemas do aparelho digestório e respiratório.

Além das plantas medicinais serem utilizadas para tratar os problemas físicos de saúde, algumas apresentam valor cultural para a comunidade como o alecrim, a arruda e o rosário (Coix lacryma-jobi), que são utilizadas para benzer. $\mathrm{O}$ ato de benzer (benzimento/benzedura) é costume da comunidade, uma forma de trazer proteção para a casa, bens e pessoas, de curar doenças, afastar ou curar males em geral.

Figura 6 - Problemas tratados com uso de plantas medicinais, na comunidade Faxinal Sete Saltos de Baixo, Ponta Grossa, PR
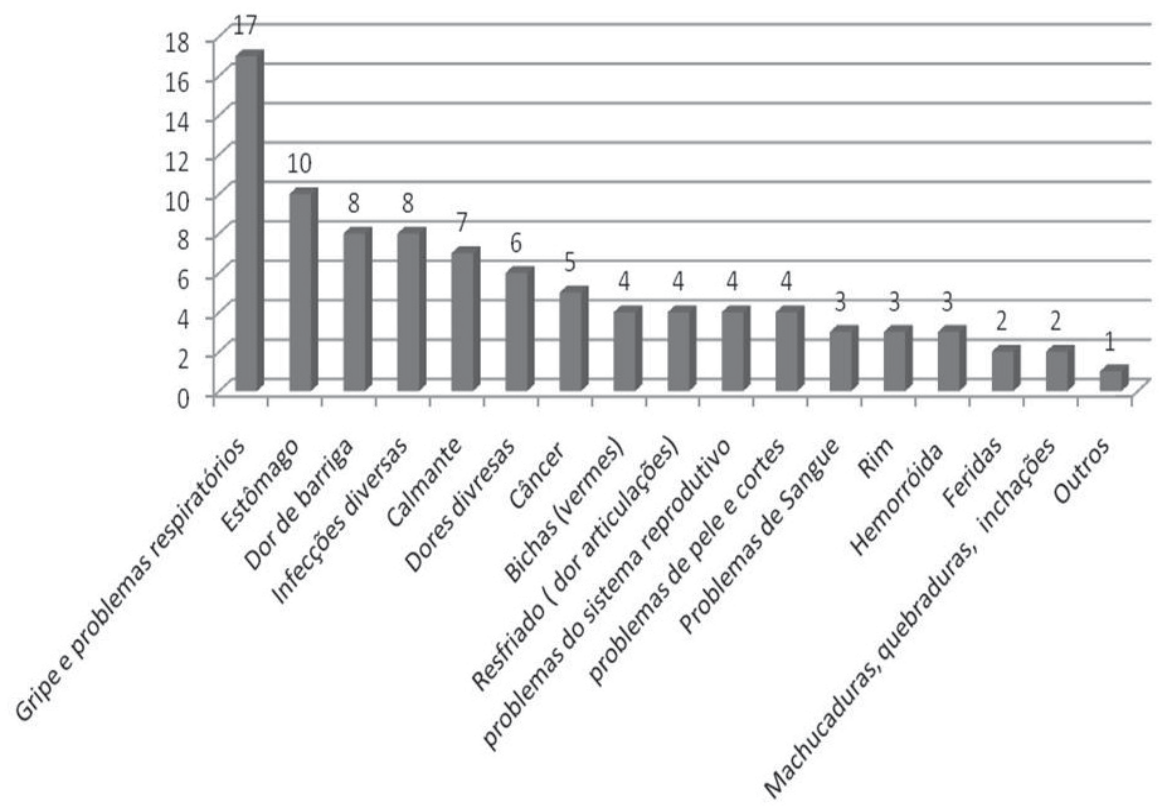

Fonte: Staniski, 2011.

Dentre as espécies de plantas medicinais citadas se destacam como mais lembradas pelos moradores as ervas, encontradas nas áreas mais próximas da casa. Já as espécies arbóreas, estão em áreas mais distantes e são pouco encontradas nas hortas-quintais, fato que colabora para terem sido menos lembradas na hora da entrevista. Outro fator 
que colabora para as ervas terem sido mais lembradas está no predomínio de informantes do sexo feminino.

Percebe-se que a localização das espécies citadas evidência uma divisão de conhecimentos e práticas dentro da comunidade estudada, onde as mulheres são as responsáveis pelas atividades diárias inerentes a casa, incluindo aqui o preparo de medicamentos. Neste sentido, são elas que carregam e reproduzem a cultura medicinal, socializando as práticas e espécies de plantas medicinais. Aos homens cabe o serviço pesado como o conserto das cercas do criadouro, agricultura e atividades que requerem deslocamento, como a busca de espécies medicinais mais distantes.

A partir da informação de que as etnoespécies são socializadas, buscou-se então descobrir qual a forma de propagação das espécies (Figura 7) utilizadas na comunidade, sendo uma das principais formas a "muda", que é para eles uma brotação das raízes, um pé que nasceu naturalmente próximo a planta advinda da semente ou um galho da planta.

Figura 7 - Forma de propagação das espécies citadas, na comunidade Faxinal Sete Saltos de Baixo, Ponta Grossa, PR

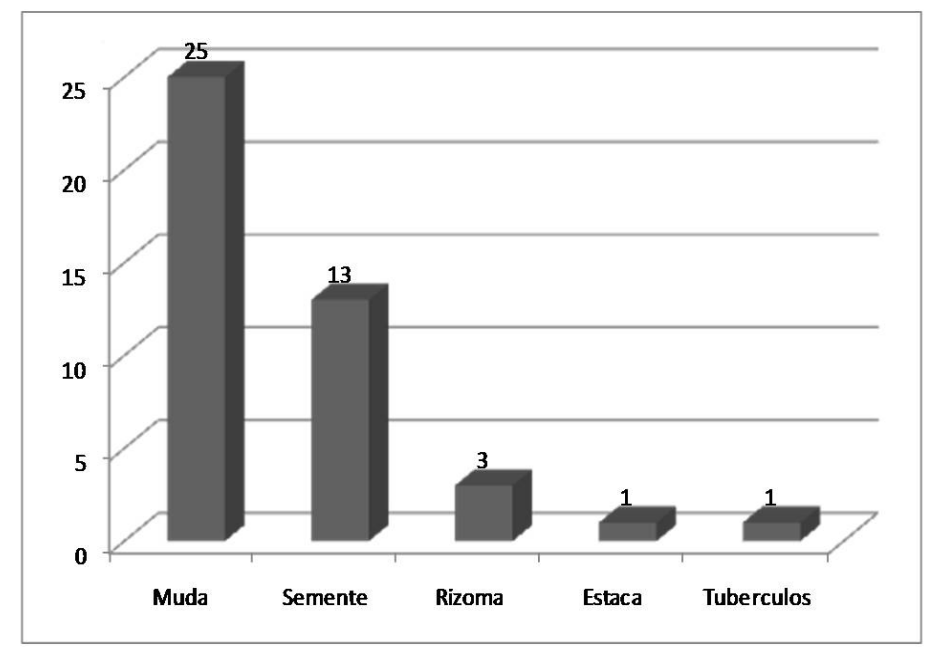

Fonte: Staniski, 2011.

Pode-se perceber que espécies nativas (do mato) as quais não foram levadas ao quintal possuem sua forma de propagação desconhecida pelos moradores, que apenas vão até a espécie quando necessitam fazer a coleta para uso. As demais espécies foram obtidas pelos entrevistados através de "mudas" e sementes, sendo estas as formas mais corriqueiras de socialização de plantas entre os moradores. Segundo Santos e Fajardo (2008) estes laços de solidariedade fazem com que as relações estabelecidas pelo contato cotidiano entre as pessoas se consolidem e se tornem mais fortes, possibilitando resolver os problemas do dia-a-dia.

A socialização (a troca) não acontece somente com medicinais, mas também com as espécies utilizadas para alimentação, ornamentação, proteção (uso cultural), havendo ainda a troca de serviços entre as pessoas. Na comunidade nenhuma planta medicinal é comercializada, somente ofertada a quem necessita. 
Quanto ao conhecimento das propriedades das plantas utilizadas para cura de enfermidades, constatou-se que este vem sendo repassado através das gerações e que as pessoas detentoras destes conhecimentos aprenderam principalmente com outras pessoas da família. Resultado similar foi obtido por Roque et al. (2010) onde os idosos aparecem nessas sociedades sendo respeitados e transmitindo seus conhecimentos para as gerações posteriores. Para Ming (2006) e Giraldi e Hanazaki (2010) essa prática é ensinada principalmente por familiares, como também por pessoas de convívio mais próximo, como vizinhos.

No entanto a comunidade ao mesmo tempo recebe influências externas, fato relatado por um dos entrevistados que citou a existência de um médico que viveu na região e que ensinou a algumas pessoas quais espécies e propriedades curativas poderiam ser extraídas para tratar problemas de menor gravidade, porém as influências externas são menos representativas frente à herança cultural transmitida pelos membros e familiares do próprio faxinal.

\section{CONSIDERAÇÕES FINAIS}

A comunidade faxinalense de Sete Saltos de Baixo demonstrou que conhece e utiliza as plantas medicinais, cujo saber é transmitido para as pessoas que buscam ou necessitam de auxílio. As plantas apresentam não somente um valor curativo das enfermidades do corpo, como também sagrado-simbólico, para curar os males da alma e buscar proteção espiritual através dos benzimentos.

Assim, perpetua-se na comunidade o hábito da socialização de fitoterápicos, o que colabora para a manutenção de espécies que possuem propriedades medicinais. As plantas, assim, simbolizam e reforçam os laços de solidariedade entre os habitantes do faxinal, que além de tudo demonstram respeito para com a natureza.

É de grande importância a manutenção dos conhecimentos sobre a medicina tradicional, para que não seja perdida essa "herança cultural adquirida através de métodos de ensaio-e-erro." (PRATA, 2007, p. 04). Em muitos lugares se constitui ainda como uma das únicas formas, e entre as de menor custo, para tratamento das enfermidades, atendendo as necessidades da comunidade de forma sustentável, sem causar danos ambientais.

Deste modo, a relevância dos estudos etnobotânicos pauta-se na valorização do conhecimento local, bem como a possibilidade de colocar duas formas de saber distintas (científica e tradicional) em possibilidade de diálogo.

\section{REFERÊNCIAS}

ALBUQUERQUE, Ulysses Paulino de; ANDRADE, Laise de Holanda Cavalcanti. Conhecimento botânico tradicional e conservação em uma área de caatinga no estado de Pernambuco, Nordeste do Brasil. Acta Botanica Brasilica, v.16, n.3, p.273-285, Jul./Set. 2002.

ALMEIDA, Maria Zélia. Plantas medicinais. 2.ed. Salvador: EDUFBA, 2003. 
ALBUQUERQUE, Ulysses Paulino de; LUCENA, Reinaldo Farias de Paiva; CUNHA, Luiz Vital Fernandes Cruz da. Métodos e Técnicas na Pesquisa Etnobiológica e Etnoecológica. Recife: NUPEEA, 2010. (Coleção Estudos e Avanços).

AMOROZO, Maria Christina de Mello. Uso e diversidade de plantas medicinais em Santo Antonio do Leverger, MT, Brasil. Acta Botanica Brasilica, v.16, n. 2, p. 189-203, 2002.

ARRUDA CAMARGO, Maria Thereza Lemos de. Os poderes das plantas sagradas numa abordagem etnofarmacobotânica. Revista do Museu de Arqueologia e Etnologia, v. 15/16, p. 395-410, 2005-2006.

ARRUDA, Rinaldo. "Populações tradicionais" e a proteção dos recursos naturais em unidades de conservação. Ambiente \& Sociedade, v. 2, n. 5, p. 79- 92, 1999.

BRASIL. Ministério da Saúde. Secretaria de Ciência, Tecnologia e Insumos Estratégicos. Departamento de Assistência Farmacêutica. Política nacional de plantas medicinais e fitoterápicos. Brasília, 2006. (Série B. Textos Básicos de Saúde).

CARMO, Marta Regina Barrotto do; MORO, Rosemeri Segecin; NOGUEIRA, Melissa Koch Fernandes de Souza. A Vegetação Florestal nos Campos Gerais. In: MELO, Mário Sérgio; MORO, Rosemeri Segecin; GUIMARÃES, Gilson Burigo. Patrimônio natural dos Campos Gerais do Paraná. Ponta Grossa: EDUEPG, 2007. p. 99- 104.

DIEGUES, Antonio Carlos. El mito moderno de la naturaleza intocada. São Paulo: NUPAUB, 2005.

DIEGUES, Antonio Carlos; ARRUDA, Rinaldo Sergio Vieira; SILVA, Viviane Capezzuto Ferreira da; FIGOLS, Francisca Aida Barboza; ANDRADE, Daniela. (Orgs.) Os Saberes Tradicionais e a Biodiversidade no Brasil. Brasília: MMA/São Paulo: USP, 2001.

DIEGUES, Antonio Carlos; VIANA, Virgílio M. (Orgs.). Comunidades tradicionais e manejo dos recursos naturais da Mata Atlântica. 2.ed. São Paulo: Hucitec/ NUPAUB-USP, 2004.

FAO. Organización de Las Naciones Unidas para la Agricultura y La Alimentacion. Departamento de Montes. Diagnostico rural participativo y análisis de genero de las comunidades atendidas por Adecogua: Pachichiac, Chicapir, la Cumbre, Pacacay y Parajbey, Tecpan Guatemala, Chimaltenango. Cidade de Guatemala: FAO, 1996. Disponível em: <http://www.fao.org/docrep/x0224s/x0224s05.html>. Acesso em: 31 ago. 2011.

FERREIRA, Everaldo Skalinski. A Influência do Sistema Faxinal no Estado Ambiental da Bacia Hidrográfica do Rio Sete Saltos - PR. 2009. Dissertação (Mestrado em Gestão do Território) - Programa de Pós-Graduação em Geografia, Universidade Estadual de Ponta Grossa. Ponta Grossa, PR.

FONSECA-KRUEL, Viviane Stern da; PEIXOTO, Ariane Luna. Etnobotânica na Reserva Extrativista Marinha de Arraial do Cabo, RJ, Brasil. Acta Botanica Brasilica, v. 18, n. 1, p. 177-190, 2004.

FLORIANI, Nicolas; CARVALHO, Silvia Méri; FLORIANI, Dimas; SILVA, Andréa Aparecida I. da; STRACHULSKI, Juliano. Modelos Híbridos de Agricultura em um Faxinal Paranaense: Confluência de Imaginários e de Saberes Sobre Paisagens. Geografia, Rio Claro, v. 36, n. 2, maio/ago. 2011.

FREITAS, Ana Valeria Lacerda. Recursos genéticos em quintais e comercialização de plantas de uso medicinal no município de São Miguel- RN. 2009. Dissertação (Mestrado em Agronomia: Fitotecnia) Programa de Pós-Graduação em Agronomia, UFERSA. Mossoró, RN.

GIRALDI, Mariana; HANAZAKI, Natalia. Uso e conhecimento tradicional de plantas medicinais no Sertão do Ribeirão, Florianópolis, SC, Brasil. Acta Botanica Brasilica, v. 24, n. 2, p. 395-406, 2010.

LATOUR, Bruno. Jamais fomos modernos: ensaio de antropologia simétrica. Rio de Janeiro: Editora 34, 1994.

LEFF, Enrique. Ecologia, Capital e Cultura: racionalidade ambiental, democracia e desenvolvimento sustentável. Blumenau: Ed. FURB, 2000.

LIMA, Lucélia Santos de. A dinâmica das territorialidades na comunidade de Faxinal do Posto Inácio Martins- PR. 2011. Dissertação (Mestrado em Geografia) - Programa de Pós-Graduação em Geografia, UNICENTRO. Guarapuava, PR. 
Lista de Espécies da Flora do Brasil 2011. Disponível em: <http://floradobrasil.jbrj.gov.br>. Acesso em: 20 jun. 2011.

Lista de Espécies medicinais, aromáticas e condimentares USP. Disponível em: <http://ci-67.ciagri.usp. br/pm/index3.asp>. Acesso em: 08 set. 2011.

LÖWEN SAHR, Cicilian Luiza. Povos tradicionais e territórios sociais: Reflexões acerca dos povos e das terras de Faxinal do bioma da mata com araucária. In: III SIMPÓSIO NACIONAL DE GEOGRAFIA AGRÁRIA/ II SIMPÓSIO INTERNACIONAL DE GEOGRAFIA AGRÁRIA JORNADA ARIOVALDO UMBELINO DE OLIVEIRA, 2005, Presidente Prudente. Anais ..., p. 1-10.

MING, Lin Chau. Plantas Medicinais na Reserva Extrativista Chico Mendes: uma visão Etnobotânica. São Paulo: Ed. UNESP, 2006.

MORO, Rosemeri Segecin; LIMA, Christiane Niedzielski de. Vegetação arbórea do Faxinal Sete Saltos de Baixo, Ponta Grossa, PR. Terr@ Plural, v. 6, n. 1, p. 79-90, jan./jun. 2012.

OKA-FIORI, Chisato; SANTOS, Leonardo José Cordeiro. (Coords.) Atlas geomorfológico do Estado do Paraná - Escala 1:250.000 modelos reduzidos. Curitiba: MINEROPAR, 2006.

OLIVEIRA, Marília Flores Seixas de; BARTHOLO JUNIOR, Roberto dos Santos. Saberes e Técnicas Medicinais do Povo Brasileiro: Corpo, Magia e Natureza, entre Pajés, Orixás e Caboclos. In: IV ENCONTRO NACIONAL DA ANPPAS (ASSOCIAÇÃO NACIONAL DE PESQUISA E PÓS-GRADUAÇÃO EM AMBIENTE E SOCIEDADE), 2008, Brasília. Anais do IV ENANPPAS. Brasília, 2008, p.1-20.

PAULA, Kamylla Barden da Silva de; CRUZ-SILVA Claudia Tatiana Araujo da. Formas de uso medicinal da babosa e camomila pela população urbana de Cascavel, Estado do Paraná. Acta Scientiarum. Health Sciences, v. 32, n. 2, p. 169-176, 2010. Disponível em: <http://periodicos.uem.br/ojs/index.php/ ActaSciHealthSci/article/view/6446>. Acesso em: 23 fev. 2011.

POSEY, Darrell Addison. Etnobiologia: teoria e prática. In: RIBEIRO, D. (Org.) Suma Etnológica Brasileira: Etnobiologia. Petrópolis, RJ: Vozes/FINEP, 1986. p. 15-25.

PRATA, Ressiliane Ribeiro. Aspectos anatômicos e etnofarmacológicos do caule e raiz de Maytenus guyanensis Klotzsch ex Reissek (Celastraceae). 2007. Dissertação (Mestrado em Ciências Biológicas,) Programa Integrado de Pós-Graduação em Biologia Tropical e Recursos Naturais, INPA/UFAM. Manaus, AM.

ROQUE, Alan de Araújo; ROCHA, Renato de Medeiros; LOIOLA, Maria Iracema Bezerra. Uso e diversidade de plantas medicinais da Caatinga na comunidade rural de Laginhas, município de Caicó, Rio Grande do Norte (nordeste do Brasil). Revista Brasileira Plantas Medicinais, v. 12, n. 1, p.31-42, jan./mar. 2010.

ROUÉ, Marie. Novas perspectivas em etnoecologia: saberes tradicionais e gestão de recursos naturais. In: CASTRO, Edna; PINTON. Florence (Orgs.). Faces do Trópico úmido: conceitos e questões sobre desenvolvimento e meio ambiente. Belém: CEJUP/UFPA/NAEA, 1997. p. 67-79.

SANTOS, Luciane Wynnek dos; FAJARDO, Sérgio. A flora medicinal nativa como uma alternativa sócioambiental na comunidade do Faxinal Rio do Couro - Irati - PR. Revista Eletrônica Lato Sensu, v. 4, p. 3, 2008.

SANTOS, Ravely Lucena; GUIMARAES, Giovane Pereira; NOBRE, Michelângela Suelleny de Caldas; PORTELA, Alyne da Silva. Análise sobre a fitoterapia como prática integrativa no Sistema Único de Saúde. Revista Brasileira Plantas Medicinais v. 13, n. 4, p. 486-491, 2011.

SILVA, Camila Bittencourt; CARVALHO, Silvia Méri. Uso e ocupação da terra na bacia hidrográfica do Rio Cachoeira, Rio Azul-PR entre 1980 e 2008. In: I SIMPÓSIO DE PESQUISADORES DE FAXINAIS: ESTADO DA ARTE E PERSPECTIVAS, 2011, Ponta Grossa. Anais ... p. 219-246.

SILVA, José Aparicio da. Fatores Endógenos e Exógenos que Levaram à Migração/ Resistência de Pequenos Produtores no Distrito de Itaiacoca- Ponta Grossa- PR, na Década de 1970. 2008. Dissertação (Mestrado em Ciências Sociais Aplicadas) - Programa de Pós-Graduação em Ciências Sociais Aplicadas, Universidade Estadual de Ponta Grossa. Ponta Grossa, PR. 
STANISKI, Adelita. Os conhecimentos tradicionais no uso de plantas medicinais: reflexões a partir da comunidade faxinal Sete Saltos de Baixo/ Ponta Grossa- PR. 2011. Monografia (Graduação em Licenciatura em Geografia) - Universidade Estadual de Ponta Grossa, Ponta Grossa, PR.

STRACHULSKI, Juliano; FLORIANI, Nicolas. Conhecimento popular sobre plantas: um estudo etnobotânico na comunidade rural de Linha Criciumal, em Cândido de Abreu- PR. Revista Geografar, v. 8, n. 1, p. 125153, jun. 2013.

STRUMINSKI, Edson; STRACHULSKI, Juliano. Uma revisão de conceitos sobre florestas em faxinais com base em uma abordagem fitogeográfica. Terr@ Plural, v. 6, n.1, p. 55-77, jan./jun. 2012.

TEIXEIRA João Batista Picinini; BARBOSA, Aretuza Ferreira; GOMES, Christiane Helena Carvalho; EIRAS, Naiara Silva Vilela. A Fitoterapia no Brasil: da medicina popular à regulamentação pelo Ministério da Saúde. 2012. Disponível em: < http:/ / www.ufjf.br/proplamed/files/2012/04/A-Fitoterapia-no-Brasil-daMedicina-Popular-\%C3\%A0-regulamenta \%C3\%A7\%C3\%A3o-pelo-Minist\%C3\%A9rio-da-Sa\%C3\%BAde. pdf> Acesso em: 24 maio 2014.

THOMÉ, Nilson. A formação do Homem do Contestado e a educação escolar - República Velha. 2006. Tese (Doutorado em Educação) - Programa de Pós-Graduação em Educação, UNICAMP, Campinas, SP.

TOLEDO, Victor Manuel; BARRERA-BASSOLS, Narciso. A etnoecologia: uma ciência pós-normal que estuda as sabedorias tradicionais. Desenvolvimento e Meio Ambiente, n. 20, p. 31-45, jul./ dez. 2009.

UNESCO. United Nations Educational, Scientific and Cultural Organization. Indigenous peoples (sic!). Disponível em: <http://www.unesco.org/new/en/indigenous-peoples/>. Acesso em: 28 abr. 2014.

VEIGA JUNIOR, Valdir Florencio da. Estudo do consumo de plantas medicinais na Região Centro-Norte do Estado do Rio de Janeiro: aceitação pelos profissionais de saúde e modo de uso pela população. Revista Brasileira de Farmacognosia, v. 18, n. 2, p. 308-313, abr./jun. 2008.

Recebido para Avaliação em 29-04-2014 Aceito para publicação em 31-07-2014 